\title{
El Inventario de la lengua castellana de José Ruiz León (1879): una propuesta lexicográfica a la Real Academia Española
}

\author{
María Águeda Moreno Moreno ${ }^{1}$ \\ Universidad de Jaén
}

\begin{abstract}
Resumen
El objetivo principal de este trabajo es dar a conocer la obra de José Ruiz León, Inventario de la lengua castellana (1879), y completar así un capítulo de la historiografía lexicográfica del español. Los datos que nos llegan del diccionario y de su autor están construidos con inexactitudes y llenos de olvidos. De ahí que con este trabajo pretendamos acceder a un conocimiento más preciso de la vida del autor, del planteamiento teórico y práctico desarrollado en su método lexicográfico, de la notoriedad de la obra en vida del autor y del posterior olvido de quien representa ser el autor de la primera obra lexicográfica de carácter ideológico.

Palabras clave: historia de la lexicografía del español, siglo XIX, diccionario ideológico, José Ruiz León, Inventario de la lengua castellana.
\end{abstract}

\footnotetext{
Para correspondencia, dirigirse a: María Águeda Moreno Moreno (magueda@ujaen.es), Departamento de Filología Española (Área de Lengua Española), Facultad de Humanidades y Ciencias de la Educación de la Universidad de Jaén. Edif. D2-028, Paraje Las Lagunillas, s/n. 23017, Jaén, España.
} 
THE INVENTARIO DE LA LENGUA CASTELLANA OF JosÉ RuIZ LEÓN (1879): A LEXICOGRAPHICAL PROPOSAL TO THE Real ACADEmia Española

Abstract

The main objective of this work is to show the work of José Ruiz León, Inventario de la lengua castellana (1879), and complete in this way a chapter of the lexicographical historiography of Spanish. The news that comes from the dictionary and its author are constructed with inaccuracies and forgetfulness. So with this work we want to give a more exact knowledge of the author's life, of the theories and practices elaborated in his lexicographical method, of the notoriety of the work in life of the author and of the later forgetting of who is the author of the first ideological lexicographical work.

Keywords: history of the lexicography of Spanish, 19th, ideological dictionary, José Ruiz León, Inventario de la lengua castellana.

Recibido: $20 / 01 / 20$

Aceptado: 07/09/20

\section{INTRODUCCIÓN}

En 1879, veintisiete años después de que Peter Mark Roget publicara su Thesaurus of English words and phrases classified and arranged so as to facilitate the expression of ideas and assist in literary composition (1852), el lexicógrafo español, José Ruiz León, publicaba el resultado de sus esfuerzos por inventariar la lengua española en un índice ideológico que quedaba relegado solo a un inventario léxico de verbos. Él mismo consideró su obra de ensayo y defiende la preeminencia del verbo, como núcleo oracional sobre el resto de unidades oracionales, como suficiente para dar a conocer la estructura de su propuesta lexicográfica. No estamos, por tanto, delante de una obra general, el Inventario de la lengua castellana (1879) solo muestra un inventario ideológico del verbo español, pero con dicho trabajo se puede conocer la dimensión teórica de la práctica lexicográfica, ya que su autor lo dotó de un extenso Prólogo (pp. XI-XLIV) en el cual podemos encontrar su método lexicográfico y el anclaje teórico que sustenta ideológica y lingüísticamente su obra. 
El objetivo de este estudio es acercarnos a su pensamiento lexicográfico y conocer directamente de sus palabras y análisis de la obra la razón que está detrás de ella. Una obra que está dedicada a la RAE, según se puede ver en la dedicatoria que hace "Á la Real Academia Española" (pp. V- IX), firmada en Madrid a 9 de noviembre de 1879 y motivada por el interés de ofrecer a la institución una muestra que sirviera de modelo para emprender la tarea de realizar un diccionario académico de carácter onomasiológico. Sin embargo, su voz ha sido una voz olvidada, de ahí que nuestro empeño también esté en conocer su lugar y su reconocimiento merecido dentro de la historia de la lexicografía del español.

\section{SOBRE JOSÉ RUIZ LEÓN (CÓRDOBA, 1823-MADRID,1888)}

Pocas, y a veces contradictorias en los datos, son las noticias historiográficas actuales que tenemos de José Ruiz de Pedrosa y León, autor del Inventario de la lengua castellana (1879), concretamente, apenas algunas notas que declaran la autoría de esta obra entre los que han escrito sobre la historia de la lexicografía del español en general, a saber, García Platero (1996) ${ }^{2}$, Alvar Ezquerra (2002), Calero Vaquera (2011) y Moreno Moreno (2013) ${ }^{3}$. Por ello es necesario buscar entre sus coetáneos noticias que nos traigan más referencias, entre las que descubrimos que, si hoy es una voz olvidada, en su tiempo gozó de importante notoriedad, reconocimiento institucional y prestigio social.

2 El propio García Platero señala: "No disponemos de muchas noticias acerca de la biografía de José Ruiz León. [nota 1]: Su nombre no aparece en las grandes enciclopedias, ni siquiera en el Índice Biográfico de España, Portugal e Iberoamérica (München; New York; London; Paris 1990) que entre sus 200000 artículos incluye datos de la mayor parte de los lexicógrafos decimonónicos" (1996: 159).

3 Recientemente se han presentado varias aportaciones a congresos internacionales sobre el autor y su obra lexicográfica, a saber: Moreno Moreno, M. ${ }^{2}-A$ A. (2019): "La práctica lexicográfica de José Ruiz León en su dimensión teórica", en I Congreso Internacional "Pensamiento, lenguas y textos" (Córdoba, 21-22 de marzo de 2019) y Moreno Moreno, M. ${ }^{a}$-Á. (2019): "El patrón de universal lingüístico para la clasificación de la lengua y la realidad de José Ruiz León (1879): un autor al margen de la práctica onomasiológica del español”, en VI Simposio internacional sobre ideología, política y reivindicaciones en lengua, literatura $y$ cine en español/italiano (Palermo (Italia), del 26 al 28 de junio de 2019). 
Su mejor semblanza la conocemos por la Necrología que en su honor realiza tras su muerte, Francisco de Borja Pavón, escritor y farmacéutico cordobés, quien compartió con Ruiz León, amistad y amor a las letras y la lengua. Si bien, cercana también en la fecha, está la breve reseña que Rafael Ramírez de Arellano, escritor e historiador cordobés, le hizo en su Ensayo bibliográfico sobre escritores de la provincia de Córdoba (1921-1923, t. I: 571-572).

Como venimos diciendo, los datos más profusos sobre su vida y obra los hallamos en la Necrología de Borja Pavón, la cual está fechada al pie el 30 de junio de 1888, apareció publicada en el Diario de Córdoba (martes, 3 de julio de 1888, núm. 11 710) y posteriormente fue recogida en el Boletín de la Academia de Ciencias, Bellas Letras y Nobles Artes de Córdoba (Año XIII, julio a septiembre 1934, núm. 34, pp. 253-259). Así sabemos que nació en Córdoba en 1823 y murió en Madrid el 22 de junio de 1888, a los sesenta y cinco años (cfr. Ramírez de Arellano 1921-23: 571 y Borja 1934: 253)4.

Sus estudios en Granada hicieron que esta ciudad fuese para él su segunda patria. Allí creó lazos de amistad y fraternidad con varios de los escritores hoy ilustres, como Pedro Antonio de Alarcón, con los cuales fue afamado de la llamada en Madrid Colonia granadina y reconocido entre ellos como "el ingeniero"s.

José Ruiz León, ingeniero de minas de profesión ${ }^{6}$, desarrolló encargos: "de objeto administrativo y benéfico en los ramos de Agricultura, de Estadística, de Comercio e Industria" (Borja 1934: 253) y desempeñó cargos oficiales en varios distritos mineros como Almadén: "provincias del Sur, de

\footnotetext{
4 A pesar de estos datos, García Platero hace una errónea interpretación en el cómputo de los años y señala la fecha de su nacimiento en 1837, a saber: "sin embargo, estos dos autores no coinciden en el dato referente a su fecha de nacimiento. Francisco de Borja Pavón señala en su necrología que el lexicógrafo cordobés contaba sesenta y cinco años en el momento de su muerte (1888), de lo que se desprende que la fecha de su nacimiento era 1837. En cambio, Ramírez de Arellano fija su nacimiento en el año de 1823" (1996: 1).

5 Pedro Antonio de Alarcón señala que, a su regreso de Berlín, vio aumentada la "Colonia" con la presencia de: "la intimidad fraternal del profundo lexicólogo y discretísimo polemista, semi-cordobés, semigranadino, José Ruiz León (el ingeniero por antonomasia)" (1891: s. p.).

6 Fruto de esa profesión son sus trabajos: Sobre las minas de plata de Hiendelaencina (Guadalajara) publicado en el Boletín oficial de minas en el que se recogía trabajos sobre materias relacionadas con la minería ¿1844-1845? (cfr. Boletín de la Comisión del Mapa geológico de España. Madrid, 1874: 82); en 1850, en el mismo boletín presentó dos trabajos: uno Sobre la minería de sierra de Gador y el otro Acerca de una mina del término de Alcolea "en el que se hacen consideraciones geognósticas sobre aquel terreno" (Id.: 97). Junto con otros especialistas escribió el Informe acerca de las obras del canal proyectado para conducir á la Habana las aguas de los manantiales de Vento: "que se imprimió en el tomo $15^{\circ}$ de la Revista Minera" (Id.: 135).
} 
Levante y Norte de España; en Guadalcanal, Almería, Castilla la Vieja y Asturias; en alguna de las regiones septentrionales de Europa y en América, en nuestras Antillas" (Id.: 254).

En Cuba se casó con Dolores Tavira y Gastón de Iriarte, natural de La Habana, hija de unos ricos hacendados y dueños del ingenio (finca azucarera) Montalvo; matrimonio del cual, ya de regreso a España, nacerían tres hijas, Rosa, María y Victoria Ruiz de Pedrosa y Tavira?.

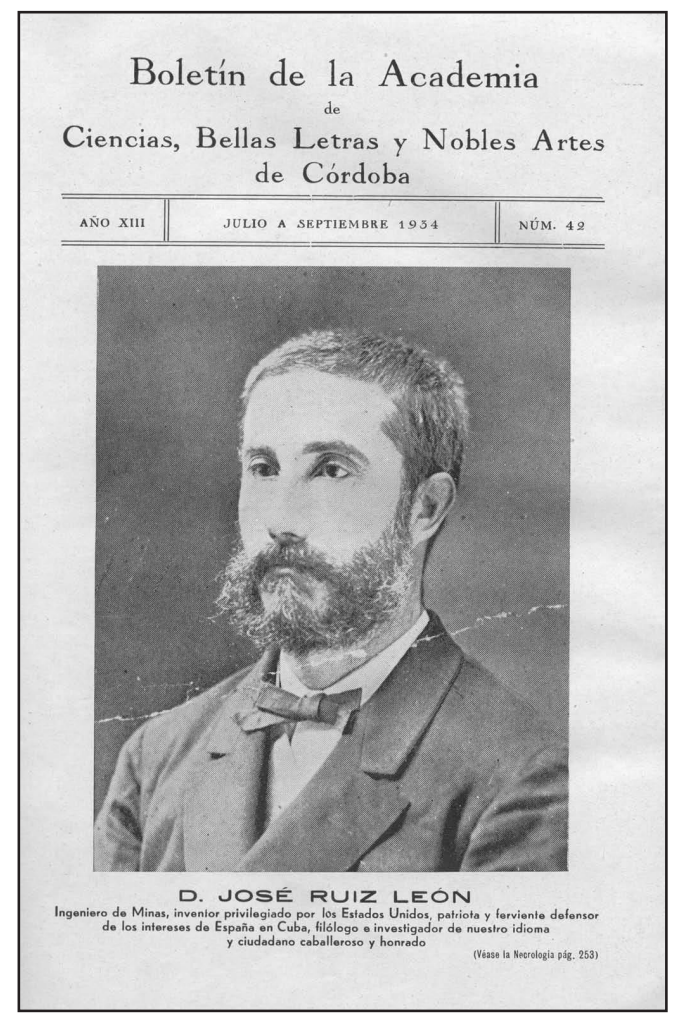

Cuadro I: Fotografía del autor

7 Los datos sobre su vida privada nos llegan gracias a un blog publicado el 11 de enero de 2015, cuyo autor anónimo se identifica como su bisnieto, nieto de Rosa Ruiz de Pedrosa y Tavira ( $c f r$. Blog La vida para el recuerdo, disponible en http://vidaparaelrecuerdo. blogspot.com/2015/01/mis-tres-abuelas.html. [Consultado 24/04/2019]. Por él sabemos que a su regreso a España el matrimonio instaló su residencia en Córdoba, "en un palacete de la calle D. Rodrigo" (Id.: ib.), en el que nacieron sus hijas. Sigue: "Por su casa pasaba todo lo más granado de la política y la literatura española. Mis abuelas, crecieron en un ambiente cosmopolita e intelectual, poco habitual en las ciudades de provincia de aquella Andalucía. Cuando mi bisabuelo murió el 22 de junio de 1888, su mujer vendió todas sus propiedades cubanas y al caer enferma nombró albacea y tutor de sus hijas a Francisco Porras Ayllón, 
Será en La Habana en donde desarrolló su iniciativa de inventor con la creación del kimasteno (Borja 1934: 255), lo que le valió el reconocimiento privilegiado de los Estados Unidos. Se trataba de un aparato, usado en una fundición de minerales que fundó, que usaba como fuerza motriz el impulso de las olas del mar, para lo cual creó una especie de playa artificial que puso a ensayo en la Isla de Cuba-Ramírez de Arellano registra el invento con el nombre de rimasteno (1921-23: 571); no ha sido posible encontrar más noticias sobre este invento y su denominación.

Interesado por los momentos sociales y políticos que vivió y entregado a la práctica de la escritura, desarrolló una prolija labor periodística en la prensa de $\mathrm{Cuba}^{8}$, como publicista director de los periódicos Diario de la Marina, periódico oficial del apostadero de La Habana (1844-1960), y La Voz de Cuba, diario político y masónico (cfr. Borja 1934: 255 y Romero 2009: 208).

quien invirtió parte del capital en las mejores fincas de la campiña cordobesa" (Id.: ib.). Rosa se casó con Juan de Dios Porras, "diputado conservador por la circunscripción de Córdoba en los años 1914 y 1916" (Id.: ib.). Y María, "con Pedro Pablo de Alarcón Contreras, hijo del íntimo amigo de su padre, el conocido escritor realista Pedro Antonio de Alarcón y Ariza" $(I d .: i b$.). El autor del blog añade: "José Ruiz de Pedrosa, además de Ingeniero de minas era un conocido lexicógrafo y pensador político, siendo el primero en proponer un diccionario ideológico de la lengua castellana" (Id.: ib.). También Ramírez de Arellano hace referencia a sus últimos años en Córdoba en la calle D. Rodrigo y al matrimonio de su hija María con el hijo de su amigo Pedro Antonio de Alarcón y Ariza (1921-23: 572); García Platero interpreta erróneamente el parentesco, señalando al escritor granadino como su "cuñado" (1996: 160), si bien, como vemos por los datos aportados, Pedro Antonio de Alarcón fue su consuegro.

8 Sirvan de ejemplo las palabras de R. Gil sobre José Ruiz León en su obra sobre la historia de la literatura de Córdoba: "Digan La Voz de Cuba y el Diario de la Marina si el señor Ruiz León no poseía vastas nociones de las cosas, propia habilidad y peculiares condiciones de buen publicista, que al escribir no lleva otros fines que los nobles y levantados propósitos del mejoramiento de las costumbres y de la prosperidad y respeto de las localidades; confirmen á una los juicios que sobre él han formado literatos de nombradía, sus artículos sueltos publicados muchos en periódicos y revistas locales" (Gil 1892: 248-249). Apunta también Borja: "Recordaremos, sin embargo, algunos escritos sueltos con que por el aguijón de los sucesos públicos solía favorecer a los periódicos de la localidad. Tales son los concernientes a los Enemigos de la Iglesia y las Huelgas, en El Amigo Católico; el informe sobre El derecho diferencial de bandera, a la Junta de Agricultura; su congratulación al Gobernador, Sr. Antúnez; por su distinguida y recta administración de esta provincia; varios artículos acerca de Los Terremotos; sus investigaciones respectivas al médico cordobés y sabio lexicógrafo Dr. Rosal, motivo de haberse logrado una copia de su obra para la Biblioteca de nuestro Ayuntamiento; su grito de indignación que con epígrafe de Una afrenta se publicó con alusión al suceso de las Islas Carolinas, como otros de sus escritos en El Comercio de Córdoba, y sus consideraciones sobre El Jurado, cuyas actuaciones en la América inglesa no le habían enamorado con exceso" (1934: 259). 
Ya en España, llevó a cabo su obra filosófico-política: Los filibusteros en Madrid y el apresamiento del "Virginius", 1874, Madrid (Imprenta de T. Fortanet), en donde trata sobre el conflicto diplomático acontecido entre España y Estados Unidos (cfr. Domingo 1990), con el apresamiento de barco Virginius para impedir una expedición ilegal de armas en auxilio de los rebeldes cubanos. La obra, como señala Borja, describe puntalmente el hecho con: "arranque de patriotismo $[\ldots \mathrm{y}]$ con gran conocimiento de la causa" (cf. Borja 1934: 256). Y su libro, Un arbitrio para gobernar á España (Madrid, 1875). Fue presentado ese mismo año en un artículo: "Un arbitrio para gobernar á España”, en la revista de renovación filosófica Revista Europea (3 de octubre de 1875), núm. 84, Año II, pp. 521-530. Como señala Borja: "este género de producciones le acreditan, cuando menos, de estadista o reformista social y de filósofo observador y de muy sana tendencia" (1934: 257). Y así es reconocido entre los escritores del derecho y la política en la Bibliografía española contemporánea del derecho $y$ de la política. 1800-1880 de Manuel Torres Campos, exbibliotecario de la Academia de Jurisprudencia y Legislación y del Ateneo de Madrid, con la reseña que se hace a esta obra en esta bibliografía (1883: 114).

\section{SOBRE SU OBRA LEXICOGRÁFICA}

De su obra lexicográfica, Inventario de la Lengua castellana: indice ideológico del Diccionario de la Academia por cuyo medio se hallarán los vocablos ignorados ú olvidados que se necesiten para hablar ó escribir en castellano: verbos, 1879. Madrid, imprenta de Fortanet ${ }^{9}$, son escasas

\footnotetext{
9 Localización: Biblioteca Nacional de Madrid. Signatura: 1/39279 (Fondo anterior a 1958). En la actualidad existe una copia digital (del ejemplar de la Biblioteca Pública de León. Colección: Pública de León. Ubicación: Fondo antiguo. Signatura: Normal FA.2386) en la Biblioteca Digital de Castilla y León (Junta de Castilla y León. Consejería de Cultura y Turismo, 2016). Disponible en http://bibliotecadigital.jcyl.es/i18n/consulta/registro. cmd?id=23954. Así mismo, con fecha de " 27 de enero de 2012" existe una edición digitalizada ("Formato: Paperback. 358 páginas. Dimensiones 189 x 246 x 19 mm.) publicada en Estados Unidos por la Editorial Nabu Press, empresa especializada en la redición de libros en formato electrónico, que utiliza mediante un proceso automatizado el texto escaneado y para las portadas fotografías genéricas de archivo. (Disponible en el repositorio digital de venta de la editorial https://www.bookdepository.com/Inventario-de-La-Lengua-Castellana-Jos-RuizLeN/9781273544392. Consultado 24/04/2019).
} 
las notas bibliográficas actuales que tenemos de ella, por la única razón de que la historia de la lexicografía del español se ha centrado principalmente en las obras más señeras de esta práctica. Ya apuntábamos más arriba las más significativas referencias historiográficas que nos traen noticias de esta obra (cfr. García Platero 1996; Alvar Ezquerra 2002; Calero Vaquera 2011 y Moreno Moreno 2013). Si bien, es en los trabajos de García Platero (1996: 159-165) y Alvar Ezquerra (2002: 324-330) en donde podemos hallar una mayor aproximación al conocimiento de la obra, lo que permite darle un espacio propio dentro del la historia de la lexicografía del español con datos complementarios y actualización bibliográfica. Algo que era absolutamente necesario, pues la Viñaza solo recogió un apunte con los datos bibliográficos básicos de la obra sin ningún tipo de comentarios: 1978, vól. III: 870 y dentro de la práctica lexicográfica ideológica, su inmediato seguidor, Benot, como director del Diccionario de ideas afines y elementos de tecnología (s. a. [1899] $)^{10}$, parece olvidarse del digno trabajo de Ruiz León cuando hace un repaso crítico a las distintas obras en las que, como él señaló, antes que él: "[han] sentido la necesidad de catalogar las palabras por sus analogías y parentescos ideológicos" (s. a. [1899]: Pról., VIII-IX). Distinta será la atención que le prestó Casares, continuador de esta tarea lexicográfica con su Diccionario Ideológico de la Lengua Española (1942), quien escribirá que la obra de Ruiz León fue: "[una] obra planeada tras largas y profundas meditaciones y llevada a cabo con paciente y honrada laboriosidad" (1921: 73).

No obstante, a pesar de las noticias actuales que encontramos sobre ella ${ }^{11}$, por los datos obtenidos, sabemos que, al menos, en vida del autor, la obra gozó de merecido prestigio y reconocimiento, como podemos ver a continuación.

10 La obra aparece sin la indicación del año de publicación. Recogemos la fecha de 1899, siguiendo la enunciación del registro y catálogo bibliográfico de la Robarts Library of Humanities \& Social Science de la University de Toronto (Canadá), en cuyo repositorio digital se encuentra la obra de E. Benot. Disponible en http://archive.org/details/ diccionariodeide00benouoft. En 1942, aparece una segunda edición en Buenos Aires, por la editorial Anaconda y con un prólogo especial para la edición argentina de Alfonso López Miranda. En la actualidad, existe una edición corregida y aumentada, con funcionalidad interactiva y texto procesado con el sistema MGARCI (Multilingüe Generador Automático de Rebusca de Concordancias e Ideas) y el título de Tesoro español o Diccionario de Ideas Afines, llevaba a cabo por Miguel Garci-Gómez de la Universidad de Duke (USA). Disponible en http://mgarci.aas.duke.edu/cibertextos/benot-e/tesoro-espanol/.

11 García Platero señala que: "la obra tuvo escasa repercusión entre el público" (1996: 160). Idea que recoge posteriormente Alvar Ezquerra (2002: 324). 


\subsection{RECONOCIMIENTOS A LA OBRA}

El Inventario (1879) se presenta en la historia de la lexicografía histórica como el primer diccionario ideológico del español. Ya en la Necrología de 1888 que le hace Borja Pavón se le reconoce esto al autor: "de profundos estudios y afición predilecta de filólogo y amante del idioma patrio, es el primero de un importantísimo trabajo, preparado con inmensa meditación y paciencia por su autor" [la cursiva es mía] (1934: 257-258). Así lo considera también Alonso Cortés cuando trata de las herramientas válidas para la escritura en su Manual de composición literaria (1939: 13). Si bien, el mayor reconocimiento en vida que recibe el autor vendría directamente de la corporación académica. Como bien señala Borja:

Recogió desde luego el aplauso de aquella corporación literaria [la RAE] en un brillante informe, y parabienes y testimonios de admiración de los más sabios y apasionados de la lengua castellana y de su literatura, así de la España peninsular como de las naciones americanas que a nuestra raza pertenecen (1934: 258).

Como confirmación de lo que señala Borja, cabe destacar que el citado informe de la RAE fue firmado en Madrid a 20 de mayo de 1880, ocho años antes de su muerte, y falló por real orden-Real Decreto de 12 de marzo de 1875 para el auxilio a publicaciones científicas- la adquisición de 100 ejemplares del diccionario por el Ministerio de Fomento para destinarlas a las bibliotecas públicas y establecimientos de instrucción. En dicho informe que apareció publicado en la Gaceta de Madrid, núm. 196 el 14 de julio de 1880, se señala que:

En cumplimiento de la órden de V. E., fecha 27 de Enero del corriente año, esta Real Academia ha examinado con detenimiento el primer tomo de la obra de D. José Ruiz Leon titulada Inventario de la Lengua Castellana, así como la instancia en que el autor solicita protección oficial, al tenor de lo dispuesto en el Real decreto de 12 de marzo de 1875 (Id.: 130) ${ }^{12}$.

El Real decreto (12 de marzo de 1875) venía a conceder auxilios para la impresión de manuscritos o para adquirir por cuenta del Estado ejemplares de las obras publicadas, tal fue el caso del diccionario de Ruiz León. Debía preceder solicitud del interesado y, como condición indispensable: "oir el parecer de la Academia ó Corporación que cultive el ramo del saber á que la

12 Disponible en https://www.boe.es/datos/pdfs/BOE//1880/196/A00129-00130.pdf. 
obra corresponda, siempre que el auxilio exceda del valor de 250 pesetas" (Real Decreto, 12 marzo 1875: art. 1). Los requisitos que la Academia o Corporación tenía que observar y determinar en la valoración de su informe eran: "que la obra ya publicada es necesario que sea original, de relevante mérito y de utilidad para las bibliotecas" [la cursiva es mía] (Id.: art. 3) ${ }^{13}$. Y efectivamente, el detenido examen a la obra dictó el auxilio del Estado. A saber:

Teniendo también en cuenta el brio, limpieza y elegancia con que están escritos, así el bien meditado prólogo como las obsequiosas páginas en que el autor dedica su obra á la Academia, opina esta Corporación que el Inventario de la Lengua Castellana merece especialísima protección y ayuda del Estado. Lo que por acuerdo de la Academia tengo la honra de comunicar á V. E., cuya vida guarde Dios muchos años. Madrid 20 de mayo de 1880. $=$ El Secretario, Manuel Tamayo y Baus. $=$ Excmo. Sr. Director general de Instrucción pública (Gaceta de Madrid, núm. 196, 14/07/1880: 130) ${ }^{14}$.

Merece la pena conocer de manera explícita las consideraciones que la Academia hizo, en donde se infiere la aceptación del plan metodológico de la obra y el reconocimiento de utilidad social obtenido de la citada Corporación. A saber:

La Academia, llamada á graduar el mérito de un trabajo que tanta relación y analogía tiene con sus tareas ordinarias, no puede menos de comenzar este informe trayendo á la memoria, como el Sr. Ruiz Leon, la junta pública inaugural de 1869, en que uno de sus individuos, el Sr. D. Francisco Cutanda, que por desgracia ya no existe, discurrió sobre la posibilidad y utilidad de clasificar metódicamente las palabras de un idioma, encareciendo como muy necesaria tal empresa, ya calificada de grande por otro ilustre Académico, el Sr. D. Nicasio Álvarez Cienfuegos, cuando al ingresar en esta Corporación el 20 de octubre de 1799 recomendaba en elocuente apóstrofe la formación de un Diccionario metódico, en que las palabras ocupasen su lugar, no según el órden alfabético, sino según el órden de las ideas. Natural era, por tanto, que una obra como la que se examina, titulada Inventario de la Lengua

13 El Real Decreto 12/03/1875 salió publicado en la Gaceta de Madrid, núm. 72, de 13/03/1875, página 676. Disponible en https://www.boe.es/datos/pdfs/BOE//1875/072/ A00676-00676.pdf.

14 Disponible en: <https://www.boe.es/datos/pdfs/BOE//1880/196/A00129-00130.pdf $>$. 
Castellana. Indice ideológico del Diccionario de la Academia, por cuyo medio se hallarán los vocablos ignorados ú olvidados que se necesiten para hablar ó escribir en castellano, obtuviera por su índole y objeto el aplauso de esta Corporación, aun ántes de entrar en el exámen de su economía, órden y estructura, y de someterla á la piedra de toque de la experiencia y de la práctica, única regla crítica que en definitiva debe aplicarse á tal linaje de producciones destinadas, más que á demostrar el ingenio propio, á servir de auxiliares al ajeno.

Para llevar á cabo tan ímproba tarea, necesitábase erudición vastísima, conocimientos filológicos muy profundos, amor entrañable al idioma patrio, penetración filosófica, sagacidad crítica, perseverancia hoy nada común, y el Sr. Ruiz Leon ha patentizado gallardamente que no carece de ninguna de estas dotes y cualidades.

Importaba sobre todo evitar el inconveniente, no salvado por los que en otras naciones se limitaron á formar algun vocabulario ideológico articulado por tan abstruso ó discrecional procedimiento, ó sea con tan arbitraria sinópsis que, lejos de prestar auxilio á quien desea hallar la expresión de su pensamiento, lo empeña en mayor fatiga, cual es averiguar ó adivinar en qué orden de ideas se le habrá ocurrido al autor del cuadro sinóptico del idioma clasificar aquel mismo pensamiento cuya expresión se busca.

Había que adoptar, por tanto, una ordenación de los vocablos por familias, por afinidades ó por congruencias, no creadas ó discernidas arbitrariamente según la filosofía propia del ordenador, sino con arreglo á nociones comunes é indiscutibles, á clasificaciones autorizadas al propio tiempo que vulgares, de las que naciesen luego bajo claves secundarias, pero también preexistentes, las múltiples variedades de los conceptos, subdivididas en la variedad de las voces, hasta conseguir encontrar, no ya el sinónimo ó el significado de la palabra como en los diccionarios alfabéticos, sino lo que pudiera llamarse el nombre de la idea.

A juicio de la Academia, el Sr. Ruiz Leon ha resuelto con felicísima sencillez este árduo problema léxico-filosófico, tomando por clave para la división primordial de su obra las partes de la oración, que oportunísimamente juzga correlativas á las formas Categorías de Aristóteles. Gracias á este arbitrio y al detenido análisis que el autor acredita haber hecho de la lengua castellana, no es menester que quien maneje su Inventario sea gran filósofo ni sabio enciclopédico, sino que tendrá bastante con saber gramática para caminar rápida $\mathrm{y}$ desembarazadamente por dentro de tan bien concertada obra, y hallar en el aparente laberinto de sus índices y catálogos las voces adecuadas á su pensamiento que no se le ocurran ó de que no tengan anterior noticia. El tomo sobre que versa este informe comprende todos los verbos castellanos, y puede servir, como ha servido á la Academia, para 
comprobar prácticamente la suma utilidad del importante y penoso trabajo del Sr. Ruiz Leon (Gaceta de Madrid, núm. 196, 14/07/1880: 130) ${ }^{15}$.

Es fácil pensar que la pronta y cercana muerte de José Ruiz León en 1888 a los sesenta y cinco años de edad, justo ocho después de este reconocimiento, limitara y determinara la continuidad del trabajo. Pues, como bien señala Borja, la obra no tuvo continuidad por: "[los] desmayos de salud y las ocupaciones del escritor" (1934: 258).

Sus propias hijas, María Ruiz de Pedrosa, viuda de Alarcón, Caridad Rosa Ruiz de Pedrosa, viuda de Porras, y Victoria Ruiz de Pedrosa y Tabira, así lo reconocerán en una reedición del Prólogo al diccionario y de la Dedicatoria a la Academia que incluyó la reedición, que harán en memoria de su padre presumiblemente a principios de siglo XX: A la memoria del señor don José Ruiz León. Académico correspondiente de la Real Academia Española. Autor del Inventario de la lengua castellana (Madrid: Librería de Leocadio López. s. f.: 40 páginas) $)^{16}$, a saber: “en 1879 publicó el primer tomo con los «Verbos», y tenía preparado el de los «Adverbios», cuando una larga enfermedad y después la muerte, en 1888, pusieron fin a todas sus aspiraciones terrenas" (Ruiz de Pedrosa, s. f.: 3). Con el título de: "Razón de este folleto" (Id.: ib.) y firma de las tres hermanas a pie de página, las editoras herederas justifican la nueva reedición de estos contenidos del Inventario señalando:

La publicación de dicho primer tomo tuvo un gran éxito; recibió felicitaciones de los principales literatos de la época, y la Academia le nombró Académico Correspondiente. Pero ha pasado mucho tiempo; todo aquello quedó olvidado y ya nadie recuerda que la primera idea de facilitar con un índice el manejo del diccionario y el primer trabajo dado a la estampa con esa finalidad, fue debido a sus (sic) iniciativa y a su estudio. Para reverdecer su recuerdo ahora, se publica el "Prólogo" y la "Dedicatoria a la Academia", contenidos en aquella edición (Ruiz de Pedrosa, s. f.: 3$)^{17}$.

15 Disponible en: <https://www.boe.es/datos/pdfs/BOE//1880/196/A00129-00130.pdf>.

16 Citamos por el ejemplar que se encuentra en la Biblioteca Histórica de la Universidad Complutense de Madrid. Sig.: BH FLL 42325. En la Biblioteca Nacional de España también se halla un ejemplar de esta reedición del prólogo y dedicatoria con la signatura VC/2211/16.

17 García Platero recoge este mismo texto del folleto de las hermanas Ruiz de Pedrosa y se lo atribuye a la RAE, a saber: "a raíz de su muerte la Real Academia Española publicó un folleto el que se reproducía una dedicatoria junto con el prólogo incluido en el Inventario, intentando paliar, en cierta manera, el injusto olvido" (1996: 160). No obstante, el autor no 


\section{2. ¿OBRA INCONCLUSA?}

Todo esto nos lleva a pensar que la obra sí tuvo un merecido reconocimiento en vida del autor, si bien luego sería un autor olvidado. Indica Casares, tal y como hemos apuntado más arriba, que la obra de Ruiz León fue una obra: "planeada tras largas y profundas meditaciones y llevada a cabo con paciente y honrada laboriosidad"18 (1921: 73), pero que: "no llegó a dar a luz más que una parte de su obra, la que comprende los verbos" (Id: ib.). En la misma línea habla Alvar Ezquerra, cuando dice: "el proyecto inicial quedó inconcluso, pues el único tomo que vio la luz recoge, sólo, los verbos" (2002: 324). Y sigue, mostrando lo que puede ser razón del estado inacabado del proyecto: "la obra no debió merecer mucho aprecio en su época, y me atrevo a pensar que no fue la casualidad la culpable del truncamiento del trabajo" [la cursiva es mía] (Id.: ib.). Este pensamiento lo infiere de unas palabras del propio Ruiz León al término del Prólogo a su obra, esto es:

Aquí acaba la prometida y un tanto enfadosa historia. Después de pensarlo bien y de tomar consejo, me he resuelto á dar á la estampa una parte del trabajo, que sirva como de muestra y ejemplar, para que con su vista pronuncie el público su inapelable fallo, declarando si acepta ó no la obra. Sin esa prueba sería atrevimiento imprimirla toda, cuyos remates exigen todavía ímprobo trabajo, amén del extraordinario costo de la edición [La cursiva es mía] (1879: Pról., XXXVI).

Intentando entender la realidad histórica de otra manera, pensamos que el autor veía en la continuidad de la obra, como él mismo señala, un "ímprobo" trabajo, de enorme aplicación, sin contar los costes editoriales, por los que, sin duda, inmediatamente presentó la solicitud al Estado de auxilio a publicaciones científicas.

debe de haber consultado la obra original a la que se refiere, pues de ser así no hubiera atribuido a la Academia la autoría de dicha reproducción.

18 Siguiendo directamente las palabras del autor en el Prólogo a su diccionario, sus reflexiones se remontan a veinticuatro años antes de la publicación, año de 1855 (1879: Pról.: $\mathrm{XI})$. 
PROLOGO.

XVII

EN RL ARTICULO.

Articulo indicativo 6 determinante. Articulo genérico 6 indetermínado,

EN EL NOMBRE SUSTANTIVO.

\begin{tabular}{|c|c|c|}
\hline \multicolumn{3}{|r|}{ Nombres diminutivos. } \\
\hline - & genéricos 6 apelativos. & despectivos. \\
\hline- & colectivos. & mumerales. \\
\hline - & aumentativos. & \\
\hline
\end{tabular}

EN EL PRONOMBRE.

Pronombres personales.

Pronombres relativos.

- demostrativos.

- indeterminador.

EN EL ADJETIVO.



EN EL VERBO.

Verbo sustantivo.

Verbos auxiliares.

- de movimiento.

Verbos de estado.

- incoativor.

- frecuentativos.

BN EL $A D V E R B I O$,

Adverbios de lugar.

- de tiempo.

- de modo.

- de cantidad.

- de comparacion.

Adverbios de órden.

- de afirmacion.

- de negacion.

- de duda.

BN LA CONJUNCTON.

Conjunciones copulativas.

- disyuntivas.

- adversativas.

- condicionales.

Conjunciones continuativas.

- causales.

- comparativas.

- Ilativas.

Cuadro II: Plan general y completo del diccionario ideológico (1879: Pról.: XVII)

La obra tiene fecha de publicación en 1879, el prólogo queda firmado a 9 de noviembre de 1879 y el informe favorable del reconocimiento de prestigio por la RAE es del 14 de julio de 1880. Así que, aunque se muestre temeroso y cauteloso ante el impacto que pudiese tener la obra en el público tras su edición, como hemos expuesto, inmediatamente obtuvo el reconocimiento de la Corporación académica; ya hemos anotado lo que a este propósito señala la RAE: 
El tomo sobre que versa este informe comprende todos los verbos castellanos, y puede servir, como ha servido á la Academia, para comprobar prácticamente la suma utilidad del importante y penoso trabajo del Sr. Ruiz Leon (Gaceta de Madrid, núm. 196, 14/07/1880: 130).

No era un reconocimiento baladí y gratuito, sino perfectamente argumentado y reglado y regulado por reglas y preceptos legales, pues la obtención del auxilio del Estado a publicaciones científicas, con el fin de declarar la importancia y el mérito de una obra "monumental y de gran coste", tal y como señala las razones fundadas del ministro de Fomento ${ }^{19}$, se materializó en el Real Decreto de 12 de marzo de 1875. Y supuso un impulso para su conocimiento y divulgación con la edición de 100 ejemplares para bibliotecas públicas por parte de Estado español.

El impacto social de la obra y del hacer de Ruiz León se ve también en distintos artículos crítico-bibliográficos que se le dedican, como: "el muy juicioso e imparcial que le consagró el Sr. Catalina García ${ }^{20}$ en la revista titulada La Ciencia Cristiana, y los de El Liberal y El Magisterio Español, periódicos de Madrid, y El Comercio de Córdoba" (cfr. Borja, 1934: 258). Así como:

19 "Cuando las altas Corporaciones, que tienen la suprema representación de las ciencias, de las letras y de las artes, declaran la importancia y el mérito de una obra monumental y de gran coste, reconociendo que necesita auxilios del Estado si se ha de llevar á término, no puede negarse tan justa protección á los cultivadores del saber, ni tampoco á las empresas editoriales, dentro de los medios con que el Gobierno cuenta para prestar su noble cooperación; pero tampoco debe limitar su ayuda á esta sola clase de publicaciones, pues el fomento de las obras de ciencia y de literatura, cuando están justificados su mérito y utilidad, por más que no consten de numerosos volúmenes ni de dispendiosas ilustraciones, ha de ser atendido por el Estado y recibir los beneficios de su protección. Cierto es que toda publicación que por su elevado coste no se halle al alcance de modestas fortunas tiene legítima preferencia en los estantes de las Bibliotecas públicas; pero la equidad aconseja que no se reduzca la cooperación oficial á esa sola clase de publicaciones, cuando la sanción de sabios Cuerpos es legitima garantía del acierto con que puede prestarse á otras, si no tan importantes materialmente, más fecundas y útiles en enseñanza y buena doctrina. Los libros de ciencia pura, que por su elevada índole tienen pocos lectores, porque los sabios no son muchos; las investigaciones históricas, utilísimas para la consulta y demasiado detalladas para ser muy leídas, y hasta los libros de amena literatura de cierta elevación en la forma y en el pensamiento, merecen y tienen derecho á exigir una justa participación en los auxilios del Gobierno" (Exposición del Ministro de Fomento, Manuel de Oriol previa a la aprobación del Decreto Real, 12/03/1875, publicado en la Gaceta de Madrid, núm. 72, de 13/03/1875, página 676. Disponible en https:// www.boe.es/datos/pdfs/BOE//1875/072/A00676-00676.pdf.)

20 Se refiere al historiador, cronista, bibliógrafo y político español, Juan Catalina García. Asiduo colaborador de revistas y medios de prensa. 
Los parabienes más o menos directos y expresivos de literatos de alta reputación como los señores Castro y Serrano, Campillo y el doctor Thebussem (el Solitario de Medina Sidonia) ${ }^{21}$ [...] uno de los más sabios y admirados por él, como ejemplo de buen saber y de modestia, le decía:-Sea cualquiera la opinión del público que tan lejos se muestra hoy de estas y otras materias, día llegará en que se reconozca que la lengua castellana es la primera que ha tenido un Diccionario completo, quiero decir, por el anverso y reverso. Si mucho ha importado siempre dar a conocer con el Diccionario común la idea correspondiente a cada palabra, más importa hoy facilitar con el Diccionario invertido a los que tienen ideas sujeridas por libros extraños (Borja 1934: 258).

De modo que, a nuestro entender, la razón de ser una obra "inconclusa" o, mejor dicho, pertenecer el Inventario a un plan general mayor que no llega a publicarse en su totalidad, obedece a otros motivos. Sin duda, a los "desmayos de salud" (Borja 1934: 258), causados por una "larga enfermedad" (Ruiz de Pedrosa s. f.: 3), tal y como señalan sus hijas, sobre todo, si sabemos que pronto moriría. Y debiera ya estar su salud quebrada al término de su obra, pues el propio autor en el Prólogo al Inventario indica, a propósito del reconocimiento al trabajo académico, que su tarea es reconocer la autoridad de la Academia: "en cuanto la escasez de mis fuerzas lo permita" (1879: Pról:: XXXIX).

Así que se puede señalar acertadamente que no fue la falta de reconocimiento público, sino los escasos días que le quedaban de vida y la delicada salud lo que, sin duda, llevaron al autor a elegir el verbo, como muestra y ensayo de su teoría y práctica lexicográfica. Tenía adelantados otros trabajos, fruto del estudio metódico recorriendo artículo por artículo el diccionario académico, así comenta: "tenía completa una de las partes en que divido los sustantivos de significación real, hecho mucho de los adverbios, algo de los adjetivos y no poco de los verbos" (Id.: XXII). Sus propias hijas señalan, tal y como ya hemos anotado, que, a la fecha de la publicación, año de 1879: “tenía preparado el de los «Adverbios», cuando una larga enfermedad y después la muerte, en 1888, pusieron fin a todas sus aspiraciones terrenas" (Ruiz de Pedrosa s. f.: 3). Restaba, por tanto, rentabilizar los esfuerzos y, partiendo de la idea de que: "el ordenamiento

21 Se refiere a los escritores del mediados del siglo XIX: José Castro y Serrano, escritor y gastrónomo, el literato sevillano Narciso Campillo y Correa y Mariano Pardo de Figueroa y de la Serna, nacido en Medina Sidonia y conocido por sus incursiones gastronómicas como el "Dr. Thebussem", apodo anagrama de la palabra "embustes" con Th. 
de las voces según las partes de la oración, da lugar á clases ó capítulos tan perfectamente distintos, que cada uno de ellos puede tratarse por separado formando cuerpo único y completo" (1879, Pról.: XXXVI), solo necesitaba optar por una opción que sirviese para dar muestra completa de su trabajo y de su ideología lexicográfica. Así dice:

Faltaba sólo dar la preferencia á una sobre las demás partes de la oración para este ensayo, y tardé poco en decidirme por el verbo, considerando que éste, palabra por excelencia (verbum), caracteriza más que otra alguna el genio del idioma, penetra, digamos, su esencia, y desempeña en la proposición oficio tan importante, que es el único vocablo que por sí sólo puede formar cabal sentido.

Sean, pues, en virtud de esa preeminencia, los verbos castellanos los destinados á dar á conocer la estructura de mi INVENTARIO (Id.: XXXVI).

\subsection{ESTRUCTURA E IDEOLOGÍA ONOMASIOLÓGICA DEL INVENTARIO}

La estructura del Inventario (1879) responde a un plan completo, bien elaborado y con un anclaje teórico que sustenta ideológica y lingüísticamente el diccionario, que forma parte de un planteamiento lingüístico de mayor envergadura, tal y como hemos visto, pero que finalmente se vio reducido a la clasificación de la categoría verbal.

Fue diseñado siguiendo un criterio puramente gramatical, en el que se atendía a la división de palabras según su función como parte de la oración. Un análisis profundo y meditado de distintas fuentes le sirvieron para adoptar este criterio. A saber, en busca de un método lexicográfico adecuado para la práctica lexicográfica onomasiológica que pretendía desarrollar, estudió la viabilidad de trasladar los modelos de los cuadros sinópticos filosóficos de los siglos XVII y XVIII; sin embargo, en ellos encontró clasificaciones impropias, insuficientes y con dificultades para adaptarlas al léxico (cfr. 1879: Pról., XIII-XIX). A propósito de esto señala:

El de aquellos filósofos, viene á ser una nomenclatura de las ciencias y de las artes: lo que aquí se busca es una ordenación de todas las nociones, desde las más sublimes y metafísicas hasta las más groseras y vulgares, no concertadas en cuerpo de ciencia, sino puestas al alcance del inquiridor por sus relaciones de analogía y parentesco, sin atender á conceptos más transcendentales (1879: Pról., XII). 
De modo que solo haya en las categorías de Aristóteles una propuesta ontológica-lingüística adecuada y natural para la clasificación de la lengua y la realidad ( $c f r$. Id.: XVI). No era una teoría peregrina:

Durante el siglo XIX y, en especial, en el período que discurre entre los años 1830 y 1880 , el número de publicaciones lingüísticas es elevado en España. Por su abundancia, diversidad y, sobre todo, por sus implicaciones filosóficas e ideológicas, merecen especial atención las gramáticas lógicas, generales y razonadas que aparecieron durante estos cincuenta años.

La especulación griega -en concreto, los principios aristotélicos, al identificar pensamiento y lenguaje, concepto y palabra- lleva a la consecuencia práctica de que una determinada concepción filosófica implica, necesariamente, una formulación gramatical peculiar (Hernández Guerrero 1982: 321).

Siguiendo estos modelos, realiza su formulación gramatical peculiar para su plan de trabajo general -véase: Cuadro II. Plan general y completo del diccionario ideológico (1879: Pról.: XVII) en este trabajo. A pesar de esto, también analizó y valoró los estudios sobre la lengua universal que "prometen" clasificaciones de ideas - como fue la obra de Bonifacio Sotos Ochando, Diccionario de la lengua universal (1886)-, sin embargo, no encontró en estas propuestas éxito para seguirlas como modelo. Como claramente señala, la diferencia de objetivos entre la obra de Ochando y su propuesta lexicográfica contaba con una: "diferencia que es fundamental en cuanto á los fines, pues que el de la lengua universal es establecer un mecanismo para denominar nuevamente los objetos, y el nuestro investigar las denominaciones que ya tienen en castellano" (1879: Pról., XXI). También se aparta del modelo lexicográfico del Thesaurus de Peter Mark Roget (1852). Para Ruiz León la organización onomasiológica del Thesaurus resulta arbitraria en la filiación ideológica y de difícil comprensión la concepción, entiende que, aunque comparten finalidad, son muchas las diferencias que presentan los modelos lexicográficos ${ }^{22}$. Véase Cuadro III:

22 Señala Casares: "el autor, que conocía el Thesaurus de Roget, se apartó del sistema de clasificación de éste, después de criticarlo con gran lucidez, pero se equivocó, a mi juicio, al tomar como base para su Inventario un criterio puramente gramatical: el de la división de las palabras según su oficio como partes de la oración" (1921: 73). Semejante es el pensamiento de Costa (cfr. 1922: 257) quien considera que el plan de clasificación es en la obra de Ruiz León arbitrario, mientras defiende una organización más conceptual, "más mental". 


\begin{tabular}{|c|c|}
\hline Thesaurus (1852) & Inventario (1879) \\
\hline Diseño filosófico, científico & $\begin{array}{c}\text { Diseño empírico (basado en la } \\
\text { experiencia y en la observación) }\end{array}$ \\
\hline Teórico para el usuario & Práctico para el usuario \\
\hline $\begin{array}{c}\text { Clasificación subjetiva } \\
\text { (a pesar de su pretensión } \\
\text { de ser general) }\end{array}$ & Clasificación gramatical \\
\hline Clasificación arbitraria & Clasificación convencional \\
\hline Difícil acceso a la información & $\begin{array}{c}\text { Acceso lógico y natural de } \\
\text { acceso a la información }\end{array}$ \\
\hline Comparten finalidad & \\
\hline
\end{tabular}

Cuadro III. Diferencias ideológicas y metodológicas de los diccionarios: el Thesaurus (1852) de P. Roget y el Inventario (1879) de J. Ruiz León

Así Ruiz León terminará diciendo:

Después de haber consultado con tan escaso fruto [...] sin poder hallar hechos de antemano los apetecidos moldes $o ́$ casillas para acomodar en ellos los vocablos de la lengua [...] decidí tomar por base y punto de partida las partes de la oración ó categorías generales [...] apelar al procedimiento práctico y analítico de recorrer el Diccionario palabra por palabra $[\ldots]$ buscar sus relaciones de semejanza, de parentesco, de alcurnia, é ir haciendo el apartado con arreglo á ellas (1879: Pról., XXII). Mientras no se invente otra que la aventaje, bien puede decirse que las "categorías" ó partes de la oración constituyen un órden, natural y racional juntamente, cuya utilidad no cabe desconocer (Id.: XXXI).

De este modo la estructura ideológica quedó sostenida en una clasificación verbal principal de cinco tipos: 1) verbo sustantivo, 2) verbos auxiliares, 3) verbos de significación material, 4) verbos de significación inmaterial y 5) verbos de la germanía.

\section{VERBOS}

1.- VERBO SUSTANTIVO

2.- VERBOS AUXILIARES

3.-VERBOS DE SIGNIFICACIÓN MATERIAL 


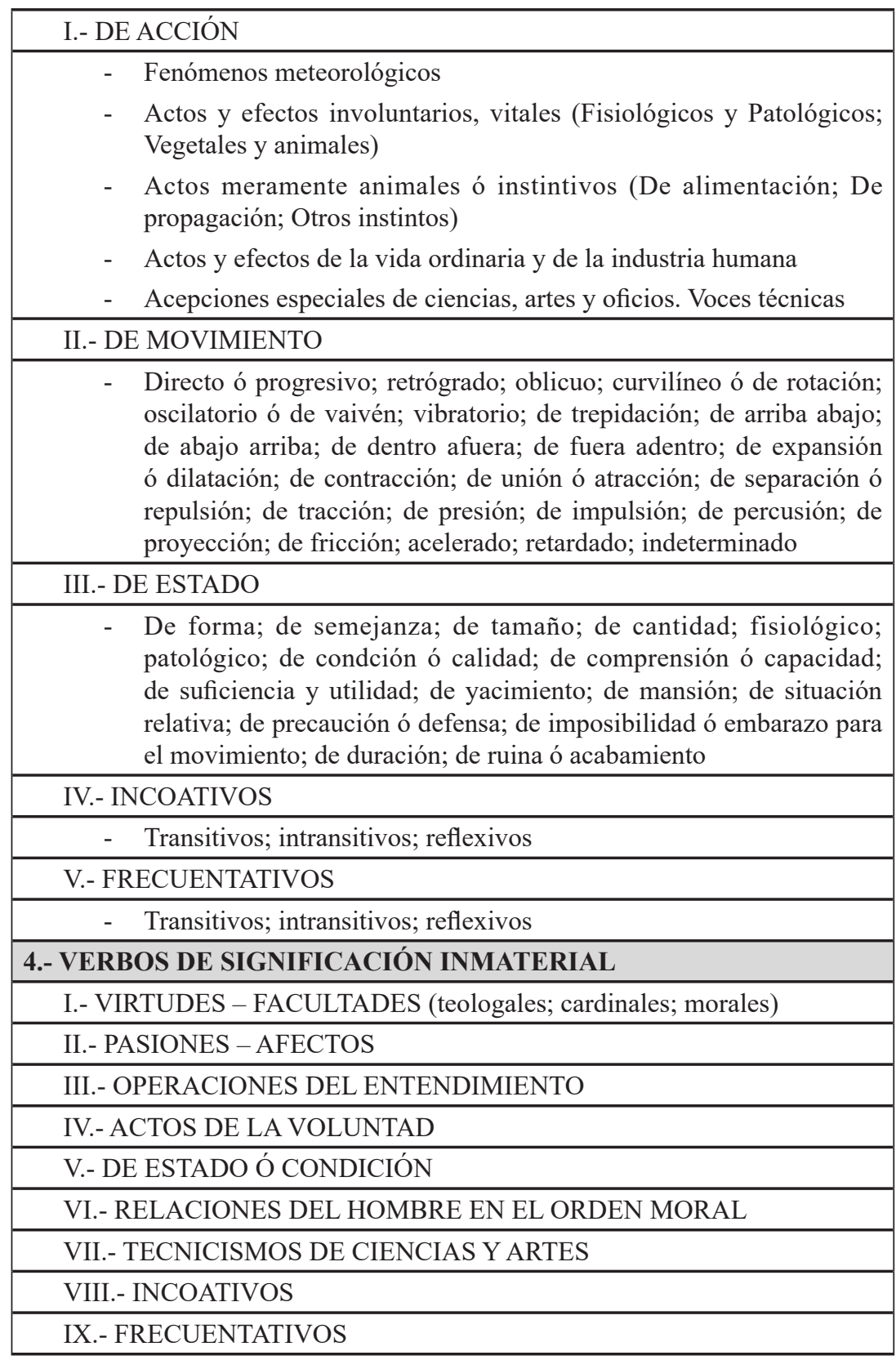




\section{5.- VERBOS DE LA GERMANÍA}

- Diferentes modos de apropiarse lo ajeno; juegos y fullerías; riñas y pendencias; mañas y tretas; relaciones de los pícaros con la justicia; otras acepciones germanescas

Cuadro IV. Estructura ideológica del Inventario (1879)

La estructura de esta propuesta ideológica responde, sin duda, al conocimiento e instrucción general de la época. Sirva de ejemplo cómo se describe el concepto de verbo sustantivo y verbo adjetivo en el Diccionario general, usual y clásico de Educación, Instrucción y enseñanza ó arte de instruirse uno mismo y de enseñar á los demás; resumen y completo de lo mejor que se ha escrito sobre los medios y modo de educar é instruir á los hombres, por mas de quinientos autores franceses, españoles, ingleses, etc. de Pío Zuazua (1848), quien a propósito de estas cuestiones remite al gramático Ángel María Terradillos y su obra: Elementos de Gramática castellana según los principios de la filosofía de los idiomas, y arreglada su ortografía á la que acaba de publicar la academia de la lengua (Segovia 1845):

VERBO SUSTANTIVO es el que designa la idea de la existencia en general, esto es, la acción de ser que á todas las cosas conviene. Ejemplo: Yo soy, yo estoy, yo fui, yo seré, \&c.

VERBO ADJETIVO. Es el que añade al verbo ser una calidad que se refiere á una acción ó á un estado como yo como, yo duermo, en lugar de yo estoy comiendo, yo estoy durmiendo.

En la lengua española hay un solo verbo sustantivo, aunque se incluyen en esta clase estar y haber que se llaman auxiliares; estar designa la existencia transitoriamente, haber, físicamente: así como ser designa la abstracta ó metafísica (Terradillos. Gram. cast.) (Zuazua 1848: 74-75).

Como vemos, Ruiz León comparte, en su primera tipología, la propuesta filosófico-ideológica de la teoría del verbo sustantivo (verbo ser) que aporta Terradillos, teoría que se inscribe en la idea del "verbo único" y que es revitalizada por la gramática general del siglo XVIII. Como bien señala Gómez Asencio:

Esta teoría, revitalizada en el siglo XVII por la Gramática de Port-Royal (1660) y rápidamente recogida (con algunas variantes que no son del caso) por la gramática general del siglo XVIII, no fue inventada por Port-Royal; es posible encontrarle antecedentes, remotos en Aristóteles y más o menos próximos en los especulativos medievales y en la tradición humanista y renacentista (1981:197). 
El segundo tipo, el verbo auxiliar, es una tipología basada en la gramaticalización y valor y/o matiz semántico que aportan los verbos acabar, deber de, dejar, eser, estar, haber, llevar, quedar, ser, seyer, soler y tener a la estructura verbal perifrástica -como aportación personal entiende que forma parte también de esta clase el verbo poder, no obstante, no lo incluye por no estar así descrito por la corporación académica. Señala: "acaso debería entrar en ella; más tampoco en esto he querido traspasar la regla establecida" (1879: Pról., XXXVII).

Los verbos de significación material y los de significación inmaterial, que ocupan los puestos tres y cuatro en el orden ideológico claramente se ajustan a una ontología filosófica. Los primeros tienen como significación material y formal el sujeto en el acto; representan acciones físicas, apreciadas por los sentidos, en definitiva, expresan la situación en que se encuentra el sujeto dentro de la oración. Los segundos, tienen como significación "lo externo" al sujeto en el acto, lo sensible e inteligible. Podemos ver ya esta clasificación en el Discurso sesión pública inaugural de la RAE en 1869 de Francisco Cutanda, quien a propósito de esto señala: "la primera y más general división de los verbos, la que se ocurre por sí misma, es en dos clases: verbos de significación inmaterial, y verbos que significan actos y movimientos materiales y, digámoslo así, tangibles" (1869: 44).

Por último, Ruiz León inventarió en la estructura ideológica los verbos de germanía. Como sabemos por sus propias palabras, el lexicógrafo toma su corpus de la lectura detenida del diccionario académico. Y también sabemos que la Academia consideró ya desde el Diccionario de autoridades (1726-39) incluir voces "de jerigonza o germanía" que llegaron al corpus académico desde la literatura áurea española. De ahí que su inclusión está justificada por la misma presencia de este léxico en la obra académica. Así señala que, tras la división gramatical que marca la obra, está la división lógica y racional del ordenamiento, que genera las clasificaciones anteriormente citadas (de significación material y significación inmaterial); y también advierte que se ha de atender de manera especial, tal y como hizo el diccionario académico, a las voces técnicas y a las de la jerga germanesca ( $c f r$. 1879: Pról., XVIII). Ruiz León incluye las voces técnicas entre los verbos de significación material -en la tabla sinóptica estos verbos se incluyen en la categoría de "acepciones especiales de ciencias, artes y oficios" (1879: Tabla sinóptica, 5). Mientras, los verbos de la jerga germanesca tendrán lugar aparte. Sin duda, podrían haberse incluido como una subestructura ideológica dentro de los verbos de significación material, pues su razón semántica es afín a dicha clasificación, sin embargo, el lexicógrafo quiso claramente diferenciar las identidades léxicas de este "oficio" del léxico de especialidad, para diferenciar un léxico técnico-especializado que representa 
un factor de cambio y evolución lingüística y es usado por un grupo social socialmente integrado, de un léxico usado por minorías sociales diferenciadas y no integradas. En la estructura ideológica, los verbos de germanía del Inventario se organizan en una clasificación temática ${ }^{23}$, esto es, de contenido semántico muy concreto relacionado con la delincuencia como oficio: 1) diferentes modos de apropiarse de lo ajeno, 2) juegos y fullerías, 3) riñas y pendencias, 4) mañas y tretas, 5) relaciones de los pícaros con la justicia y 6) otras acepciones germanescas.

Con ello también muestra la distancia que ofrece su obra frente al Thesaurus (1852) de Roget: el Inventario posee un diseño empírico (basado en la experiencia y en la observación), distinto del diseño inglés de carácter absolutamente filosófico y científico. Así señala: "entra después el autor [se refiere a P. Roget] á exponer y discutir las razones que tuvo para conservar ó nó en su catálogo ciertas expresiones vulgares" (1879: Pról., XXIV). A lo que sigue: "aquí, por el contrario, no se trata de discutir ni de juzgar acerca de la propiedad de las voces, ni de disminuir ni de aumentar el caudal de la lengua, sino meramente de ordenar los vocablos admitidos por la Academia" (Id.: ib.).

\section{A MODO DE CONCLUSIÓN}

Aparte del trabajo de análisis, estudio y clasificación de las voces registradas que desarrolló José Ruiz León en su Inventario (1879), merece mención especial su Prólogo a la obra. Un prólogo de más de una treintena de páginas (Id.: XI-XLIV), nada habitual para este tipo de obras, y esto no solo ya por la extensión, sino por su carácter. El Prólogo, tal y como hemos podido ver por las anotaciones que hemos hecho a su contenido, actúa como un claro componente lexicográfico paratextual, no es un prólogo laudatorio al uso. El prólogo tiene su propia función pertinente para la obra lexicográfica: sirve de guía para el usuario, pero sobre todo sirve para tener conocimiento del método lexicográfico llevado a la práctica y del método científico

23 Como bien apunta Lara: "la germanía, como las jergas en general, no es un "lenguaje", sino como tal se ha de entender que tiene su propia gramática y su propio diccionario. Es un vocabulario restringido a unos cuantos temas relacionado con las prácticas y las experiencias de los delincuentes. No de todos los delincuentes, sino de aquellos que practican el delito como oficio" (2016: 199). 
desarrollado para reforzar con validez los resultados. De su lectura podemos conocer la serie de pasos sistemáticos e instrumentos utilizados para llevar a cabo la elaboración del diccionario: los cuadros sinópticos filosóficos de los siglos XVII y XVIII; las gramáticas lógicas y generales del siglo XIX; las teorías de los siglos XVIII-XIX sobre la "lengua universal"; el método ideológico de la lexicografía inglesa de diccionario de Roget; pero sobre todo, la propuesta ontológica-lingüística, para él natural y adecuada para la clasificación de la lengua y la realidad, de las categorías aristotélicas y los textos discursos académicos de Nicasio Álvarez-Cienfuegos (1799) y Francisco Cutanda (1869), sobre el orden alfabético y la ordenación lógica. Es la muestra explícita del resultado directo de la observación, de la experimentación y del análisis e interpretación de la lengua. Sin duda, un "diario del lexicógrafo", que, por este valor, mereció que sus propias hijas volvieran a llevarlo a la imprenta.

De igual manera es necesario destacar el proemio o discurso que dedica a la Real Academia Española (1879: V-IX). Antepuesto al Prólogo, este discurso se hace para dar total sentido a la obra lexicográfica: el Inventario es un modelo, una propuesta de ordenación onomasiológica para que la RAE pueda tenerlo de guía y ponerlo en práctica. De modo que la "imperfección" que en ella se pueda hallar por no ser una obra completa, se enmienda al presentarla como: "muestra y ejemplar" de un método lexicográfico (1879: Pról., XXXVI).

El proemio a la RAE se presenta como un exordio con el fin de atraer la atención, preparar el ánimo y, sobre todo, obtener la buena voluntad y benevolencia de la corporación académica. Así que, aunque como parte de la técnica de la escritura se presenta como un lexicógrafo modesto -"para disculpar el atrevimiento de quien sin título ni saber acomete la ardua tarea de inventariar y ordenar metódicamente los ricos caudales de la lengua castellana" (1879: Pról., V)-, señala que su obra es una "obra dictada por el entendimiento" y, además es "una obra patriótica" (Id.: ib.), pues trata temas que son de interés público y personal, esto es, el purismo lingüístico y el rechazo de los extranjerismos por innecesarios. Así escribe: "a la Real Academia corresponde el primer puesto de tan noble cruzada contra infieles prevaricadores del buen lenguaje" (Id.: VIII), pues, a su juicio: "los documentos oficiales [están] plagados de vocablos peregrinos, de locuciones impropias é inadmisibles, y de neologismos y barbarismos repugnantes" (Id.: ib.). De esto también nos da razón las palabras sobre su semblante que le dedica Borja:

Cervantista de vocación, como quien sabía de memoria la novela inmortal del glorioso manco, mostrábase censor severo de lo que en dicción o frase 
no revelaba purísimo abolengo, aplicando un rigorismo a lo Baralt, y su lápiz rojo a escritos que por otra parte le cultivaban, como el talento de sus autores. Tal intolerancia suelen oponer los puritanos del idioma, a la de los neologistas que abundan más y a quienes escuecen en cierta manera palabras y modismos, hoy en desuso bien o mal sancionado (1934: 259).

En cuanto al método lexicográfico, el proceso onomasiológico se presenta como un orden lógico y racional, ya que considera que es solicitud natural de consulta por el usuario. Para él el orden alfabético (proceso semasiológico) no ofrece un verdadero acceso al significado, sino al significante, es: "inclemente é irracional" (1879: Pról., XII). Señala: "solo sirve para explicarnos lo que ya sabemos: conocida una voz, él fija la propiedad de sus acepciones y determina su ortografía; más para el caso inverso no hay en él solución posible" (Id.: ib.). Por su parte, la puesta en práctica del método implica una clara intertextualidad, pues la vinculación explícita con el diccionario académico influye directamente en el contenido macroestructural del Inventario. La originalidad no descansa en el repertorio léxico, sino en la estructura y la interpretación de su significado.

En definitiva, con la obra de Ruiz León, no solo estamos ante el primer producto lexicográfico de corte ideológico del español, sino que, tras su conocimiento, somos capaces de asegurar que estamos ante una obra original, completa teóricamente (si bien forma parte de una empresa mayor que no logró ser realizada), que disfrutó de notoriedad y reconocimiento en su época, pues su discurso encajaba perfectamente entre los que triunfaban en el momento, pero que tras la muerte del autor, su voz cayó en el olvido y su obra nunca entró a formar parte del canon tenido en cuenta para la práctica lexicográfica.

Al cabo, sirva este trabajo para un mayor acercamiento a la obra de Ruiz León, en particular, y al conocimiento del desarrollo de la práctica lexicográfica ideológica del español, en general.

\section{REFERENCIAS BIBLIOGRÁFICAS}

Alarcón, Pedro Antonio De. 1891. Últimos escritos. Madrid: Imprenta y Fundición de M. Tello [en línea]. Disponible en http://www.cervantesvirtual.com/obra-visor/ ultimos-escritos--0/html/ff086776-82b1-11df-acc7-002185ce6064_3.html/marca/ Jos\%C3\%A9\%20Ruiz\#264 [Consulta 04/09/2020].

Alonso Cortés, NARCiso. 1939. Manual de composición literaria. Valladolid: Librería Santaren [en línea]. Disponible en https://bibliotecadigital.jcyl.es/es/catalogo_imagenes/ grupo.cmd?path=10066937 [Consulta 04/09/2020]. 
Alvar Ezquerra, Manuel. 2002. De antiguos y nuevos diccionarios del español. Madrid: Arco/Libros.

Álvarez-Cienfuegos, Nicasio. 1799. Estudio de la filología en su relación con las demás ciencias, discurso de ingreso en la RAE. En Memorias de la Academia Española, t. I, 1870 , pp. 358 y ss.

Benot, Eduardo. S.A. [1899]. Diccionario de ideas afines y elementos de tecnología. Madrid: Mariano Samper editor.

Boletín de LA COMISIÓN DEl MAPA GeOlóGICo de EsPaÑa. 1874. Madrid. [en línea] Disponible en http://hemerotecadigital.bne.es/details.vm? $\mathrm{o}=\& \mathrm{w}=0211-0245 \& \mathrm{f}=\mathrm{issn} \& \mathrm{l}=500$ [Consulta 09/12/2020].

Borja Pavón, Francisco De. 1934. Necrología de D. José Ruiz León. Boletín de la Academia de Ciencias, Bellas Letras y Nobles Artes de Córdoba. Año XIII, julio a septiembre 1934, núm. 34, pp. 253-259 [en línea]. Disponible en http://repositorio.racordoba.es/jspui/ handle/10853/45 [Consulta 04/09/2020].

Calero Vaquera, M. a Luisa. 2011. Germen de un nuevo género: el diccionario ideológico. En Félix San Vicente; Cecilio Garriga; Hugo Lombardini (eds.). Estudios de Lexicografía e Ideología, pp. 137-149. Monza: Polimetrica International Scientific Publisher

Casares y Sánchez, Julio. 1921. Nuevo concepto del Diccionario de la lengua. Discurso leido en el acto de su recepción [en la RAE]. Madrid [en línea]. Disponible en http://www. rae.es/sites/default/files/Discurso_de_ingreso_Julio_Casares.pdf [Consulta 04/09/2020].

Casares, Julio. 1977 [1942]. Diccionario Ideológico de la Lengua Española, 2. ${ }^{\mathrm{a}}$ ed., 8. ${ }^{\mathrm{a}}$ tirada. Barcelona: Gustavo Gili.

Costa Álvarez, Arturo. 1922. Nuestra lengua. Sociedad Editora Argentina.

CutANDA, Francisco. 1869. Discurso (sesión pública inaugural de la RAE). Madrid: Imprenta y estereotipia de M. Rivadeneyra.

Diario de Córdoba. De comercio, industria, administración, noticias y aviso. 3 de julio de 1888. Núm. 11 710, Año XXXIX [en línea]. Disponible en http://prensahistorica.mcu. es/es/publicaciones/numeros_por_mes.do?idPublicacion=7407\&anyo=1888 [Consulta 04/09/2020].

Domingo Acebrón, M. ${ }^{a}$-Dolores. 1990. El tráfico de armas durante la Guerra de los diez años (1868-1878). Tebeto: Anuario del Archivo Histórico Insular de Fuerteventura 3: 91 132 [en línea]. Disponible en https://dialnet.unirioja.es/servlet/articulo?codigo=2235485 [Consulta 04/09/2020].

Gaceta de Madrid. 14 de julio de 1880. Núm. 196 [en línea]. Disponible en https://www.boe. es/datos/pdfs/BOE//1880/196/A00129-00130.pdf [Consulta 04/09/2020].

García Platero, JuAn Manuel. 1996. El Inventario de la lengua castellana de José Ruiz León. En Manuel Alvar Ezquerra (coord.) Estudios de historia de la lexicografia del español, pp. 159-165. Málaga: Servicios de publicaciones. (Estudios y ensayos / Universidad de Málaga. Filología, 6).

GiL, Rodolfo. 1892. Córdoba contemporánea. Apuntes para la Historia de la Literatura en esta provincia desde el año 1859, en que se celebraron los primeros Juegos florales hasta el próximo pasado 1891. Córdoba: Imprenta y Papelería Catalana.

GómeZ AsEnCiO, José Jesús. 1981. Gramática y categorías verbales en la tradición española (1771-1847). Salamanca: SPU.

Hernández Guerrero, José Antonio. 1982. Filosofía y Gramática: una polémica "ideológica” en el siglo XIX. Revista Española de Lingüística II/12: 321-356.

Lara, Luis Fernando. 2016. Teoría semántica y método lexicográfico. México: El Colegio de México AC.

Moreno Moreno, M. a ÁGueda. 2013. El método lexicográfico onomasiológico de Eduardo Benot [1899]. Études Romanes de Brno 34/2: 23-39. 
Ramírez DE ARELlano, RAFAel. 1921-1923. Ensayo de un catálogo biográfico de escritores de la provincia y diócesis de Córdoba, con descripción de sus obras, 2 t. Madrid: Tip. de la Revista de Archivos, Bibliotecas y Museos [en línea]. Disponible en http://www. bibliotecavirtualdeandalucia.es/catalogo/es/consulta/registro.cmd?id=1000479 [Consulta 04/09/2020].

Roget, Peter-Mark. 1865 [1852]. Thesaurus of English words and phrases classified and arranged so as to facilitate the expression of ideas and assist in literary composition. Boston: Gould and Lincoln.

Romero DomíngueZ, LoRENA R. 2009. La buena prensa: prensa católica en Andalucía durante la Restauración. Sevilla: Centro de Estudios Andaluces [en línea]. Disponible en https:// books.google.es/books?id=LH8eLWhqL3cC\&printsec $=$ frontcover\&hl=es\&source $=$ gbs ge_summary_r\&cad $=0 \# \mathrm{v}=$ onepage $\& \mathrm{q} \& \mathrm{f}=$ false [Consulta 04/09/2020].

RuIz León, José. 1874. Los filibusteros en Madrid y el apresamiento del “Virginius", Madrid: Imprenta de T. Fortanet.

1875. Un arbitrio para gobernar á España. Madrid. Otra ed.: "Un arbitrio para gobernar á España”, Revista Europea (3 de octubre de 1875), núm. 84, Año II: 521530 [en línea]. Disponible en http://www.filosofia.org/rev/reu/1875/pdf/n084p521.pdf [Consulta 04/09/2020].

1879. Inventario de la lengua castellana. Índice ideológico del diccionario de la Academia por cuyo medio se hallarán los vocablos ignorados ú olvidados que se necesiten para hablar ó escribir en castellano. Verbos. Madrid: Imprenta de Fortanet.

Ruiz de Pedrosa, María, Caridad Rosa y Victoria (eds.). s. f. A la memoria del señor don José Ruiz León. Académico correspondiente de la Real Academia Española. Autor del Inventario de la lengua castellana. Madrid: Librería de Leocadio López.

Sotos Ochando, Bonifacio. 1886. Diccionario de la lengua universal. Buenos Aires: Taller tipográfico de la Penitenciaría.

Terradillos, Ángel María. 1845. Elementos de Gramática castellana según los principios de la filosofía de los idiomas, y arreglada su ortografía á la que acaba de publicar la academia de la lengua. Segovia: Imp. de los sobrinos de Espinosa [en línea]. Disponible en http://bdh-rd.bne.es/viewer.vm?id=0000207856\&page=1 [Consulta 04/09/2020].

Torres CAMpos, Manuel. 1883. Bibliografía española contemporánea del derecho y de la política. 1800-1880. Guía de los juristas y políticos. Madrid: Librería de D. Fernando Fe [en línea]. Disponible en http://fama2.us.es/fde/ocr/2006/ bibliografiaDeDerechoT1. pdf [Consulta 04/09/2020].

Viñaza, CONDE DE LA. 1978. Biblioteca histórica de la Filología Castellana, 3 vól. RAE: Madrid.

Zuazua, Pío. 1848. Diccionario general, usual y clásico de Educación, Instrucción y enseñanza ó arte de instruirse uno ismo y de enseñar á los demás; resumen y completo de lo mejor que se ha escrito sobre los medios y modo de educar é instruir á los hombres, por mas de quinientos autores franceses, españoles, ingleses, etc. San Sebastián: Imprenta y Librería de Pío Baroja. 